\title{
Gain of Chromosomal Region $3 q 26$ as a Prognostic Biomarker for High-Grade Cervical Intraepithelial Neoplasia: Literature Overview and Pilot Study
}

\author{
Margot M Koeneman ${ }^{1,2}$ (D) Irene T Ovestad ${ }^{3} \cdot$ Emiel A. M. Janssen ${ }^{3,4} \cdot$ Monique Ummelen $^{2,5}$ • \\ Roy F. P. M. Kruitwagen ${ }^{1,2}$ • Anton H. Hopman ${ }^{2,5}$ • Arnold J. Kruse 1,2,6
}

Received: 18 August 2018 / Accepted: 4 October 2018 / Published online: 25 October 2018

(C) The Author(s) 2018

\begin{abstract}
Approximately $20-40 \%$ of high-grade Cervical Intraepithelial Neoplasia (CIN) regresses spontaneously, but the natural prognosis of an individual lesion is unpredictable. Gain of the chromosomal 3q region, which contains the human telomerase RNA gene on $3 q 26$, is found in CIN lesions and cervical carcinoma and shows correlation with disease grade. The aim of this study is to assess whether $3 q 26$ gain as a single genetic marker can predict the natural prognosis of highgrade CIN, by performing a review of the literature and pilot study. A literature review was conducted. Additionally, we performed a pilot study in 19 patients with histologically confirmed high-grade CIN lesions who were followed for a mean of 115 days, after which loop excision was performed. Fluorescent in situ hybridization analysis was performed on the initial diagnostic biopsies to determine gain of $3 q 26$. Eight studies were included in the literature overview, with a total of 407 patients. Of these, only 22 patients had high-grade lesions. All studies found an association between $3 q 26$ gain and disease prognosis. Positive predictive values (PPV) ranged from 50 to $93 \%$, negative predictive values (NPV) ranged from 75 to $100 \%$. Only five out of 155 patients (3.2\%) without $3 q 26$ gain showed disease persistence or progression. In our pilot study on $3 q 26$ gain in high-grade CIN, the PPV of $3 q 26$ gain for disease persistence was $67 \%$, the NPV 100\%. All four patients without $3 q 26$ gain showed disease regression. In conclusion, the absence of $3 q 26$ gain in diagnostic biopsies may be applied to identify high-grade CIN lesions with a high probability of disease regression.
\end{abstract}

Keywords $h T E R C \cdot 3 q 26 \cdot$ Cervical intraepithelal neoplasia $\cdot$ Prognosis $\cdot$ Biomarker

Margot M Koeneman

margot.koeneman@mumc.nl

Irene T Ovestad

irene.tveiteras.ovestad@sus.no

Emiel A. M. Janssen

emilius.adrianus.maria.janssen@sus.no

Monique Ummelen

m.ummelen@maastrichtuniversity.nl

Roy F. P. M. Kruitwagen

r.kruitwagen@mumc.nl

Anton H. Hopman

hopman@maastrichtuniversity.nl

Arnold J. Kruse

arnoldjankruse@hotmail.com
1 Department of Obstetrics and Gynecology, Maastricht University Medical Centre, Maastricht, the Netherlands

2 GROW - School for Oncology and Developmental Biology, Maastricht University, Maastricht, the Netherlands

3 Department of Pathology, Stavanger University Hospital, Stavanger, Norway

4 Department of Mathematics and Natural Science, University of Stavanger, Stavanger, Norway

5 Department of Molecular Cell Biology, Maastricht University, Maastricht, The Netherlands

6 Department of Obstetrics and Gynecology, Isala Clinics, Zwolle, The Netherlands 


\section{Introduction}

High-grade Cervical Intraepithelial Neoplasia (CIN) is caused by Human Papillomavirus (HPV)-infection and is considered to be the precursor of cervical carcinoma [1]. Approximately $30 \%$ of high-grade lesions progresses to cervical cancer on the long term, whereas spontaneous regression occurs in approximately $20-40 \%$ [2-6]. Conventional histopathological assessment is unable to differentiate between high-grade lesions that will progress to cervical cancer and those that will regress spontaneously. Consequently, most high-grade lesions are currently treated, leading to significant overtreatment with associated side-effects [7]. Ideally, the natural prognosis of individual CIN lesions would be predictable, in order to select patients in whom spontaneous regression is expected for a wait-and-see policy.

It has been established that the development of $\mathrm{CIN}$ and concurrent progression to cervical cancer is influenced by a complex interaction between HPV, the host immune system and functional cellular mechanisms [8,9]. Cervical oncogenesis is characterized by several genetic effects, among which are genomic instability, chromosomal aberrations and integration of viral DNA into the host genome. Markers of these processes have been identified as potential diagnostic or prognostic biomarkers in the diagnosis and prognosis of CIN [10, 11]. Among these is chromosomal region $3 q$ gain, which is frequently found in cervical carcinomas and its precursor lesions [12]. The association between 3q gain and cervical oncogenesis may be caused by amplification of the human telomerase RNA gene ( $h T E R C$ ), which is localized on the $3 q 26$ locus. The $h T E R C$ gene encodes for the RNA unit of telomerase, which maintains the length of telomeres through cellular divisions. Overexpression of $h T E R C$ leads to the avoidance of abnormal cells with critically short telomeres to undergo apoptosis, which is a contributing factor in oncogenesis. Gain of $3 q 26 / h T E R C$ or copy number variations has been shown to correlate with disease grade in cervical lesions and could function as a diagnostic tool in cervical pathology [13-16]. Several studies have addressed the prognostic properties of $3 q 26 /$ hTERC gain in the natural prognosis of CIN, but most studies focussed on low-grade lesions and/or evaluated $3 q$ gain in cytological specimen. Evidence on $3 q$ gain in histologically confirmed high-grade CIN is very scarce. The goal of this study is to provide an overview of the literature on the prognostic properties of $3 q 26 / h T E R C$ gain in the natural prognosis of CIN and to investigate the predictive properties of $3 q 26$ gain specifically in high-grade CIN.

\section{Materials and Methods}

The study was performed according to the PROBE criteria for biomarker research, where possible and applicable.

\section{Patient Population}

For the pilot study, the patient population was extracted from a prospective population based cohort study, conducted at the Stavanger University Hospital, Norway [5]. The women in this cohort were diagnosed with a CIN2 or CIN 3 lesion in a diagnostic biopsy. All biopsies were stained for Hematoxylin Eosin, p16 and Ki-67 and disease grade was based on the most severely dysplastic area with the most intensive Ki-67 and p16 staining. Staining was assessed for disease grade by consensus scoring of three observers, followed by independent quality control of a fourth observer. All used the same microscope $(40 \times$ objective $0.52 \mathrm{~mm}$, numerical aperture 0.65$)$. All women underwent a Loop Electrosurgical Excision Procedure (LEEP) after a median of 113 days follow-up (range 84171 days). The natural history of the baseline cervical lesion during the follow-up period was evaluated in the LEEP specimen. Regression was defined as CIN1 or less in the LEEP specimen. Further details on histological evaluation, HPV genotyping and lesions size measurements can be found in the original article [5]. Out of this cohort, representative and sufficient baseline biopsy material for $3 q 26$ analysis was available for 19 patients. These patients were included in the pilot study.

\section{FISH Procedure}

FISH analysis was performed on the baseline biopsies. The $3 q$ specific FISH was performed on $4 \mu \mathrm{m}$ thick FFPE tissue sections fixed onto Superfrost Plus Microscope Slides (Thermo Fisher Scientific). The tissue sections were first heated for $15 \mathrm{~min}$ at $80^{\circ} \mathrm{C}$, then dewaxed, hydrated and microwaved for $10 \mathrm{~min}$ at $100{ }^{\circ} \mathrm{C}$ in a $10 \mathrm{mM} \mathrm{Na}$-Citrate $\mathrm{pH}$ buffer and incubated at room temperature for $20 \mathrm{~min}$ to cool down. Subsequently, the sections were washed in demineralized water, rinsed in $0.01 \mathrm{M} \mathrm{HCl}$ and digested with $2.5 \mathrm{mg}$ of pepsin in $0.01 \mathrm{~N} \mathrm{HCl}$ and post-fixed in $1 \%$ formaldehyde in PBS for $5 \mathrm{~min}$ at room temperature. Subsequently, the 3 centromere probe (p $\alpha 3.5$ ) and 3q26 probe (3q26.1: BAC23 RP11-264D7, Map position 3q26.1-26.3 close to the TERC locus), were labeled with Digoxigenin (3c) and Biotin (3q) in a nick translation labelling (Jena Bioscience GmBH, Jena, Germany). The probes were hybridized at a concentration of $2 \eta \mathrm{g} / \mu \mathrm{l}$ (3c), $5 \eta \mathrm{g} / \mu \mathrm{l}(3 \mathrm{q}) ; 10 \mathrm{x}$ excess COT, and $75 \mathrm{x}$ excess of carrier DNA (salmon sperm DNA) in 50\% formamide; $2 x$ SSC; $10 \%$ dextran sulphate. The probe was applied under a coverslip, simultaneously denatured for $10 \mathrm{~min}$ at $80^{\circ} \mathrm{C}$ and hybridized overnight at $37^{\circ} \mathrm{C}$. After hybridization, the preparations were washed for $5 \mathrm{~min}$ at $61{ }^{\circ} \mathrm{C}$ in a solution, containing $2 \times \mathrm{SSC}$, $0.05 \%$ tween-20 (Janssen Chimica, Beerse, Belgium) and $0.1 \times$ SSC (the washing was carried out twice). The hybridized FISH probe was detected with a triple layer detection method, consisting of 1. FITC-conjugated avidin (Av-FITC, 
1:100 dilution, Vector Laboratories) / Monoclonal antiDigoxigenin (M $\alpha$ Dig, 1:100 dilution, Sigma, USA, St Louis $\mathrm{MO}) ; 2$. Botinylated Goat anti-Avidin (Bio-G $\alpha$ A, 1:100 dilution, Vector Laboratories USA) / Rabbit anti Mouse-TRITC (1:100 dilution, Dako, Glostrup, Denmark) and 3. Av-FITC / Swine anti Rabbit-TRITC (1:100 dilutionDako). Finally, the slides were washed in PBS containing $0.05 \%$ Tween-20, dehydrated in an ascending ethanol series and mounted in Vectashield (Vector Laboratories), containing DAPI (Sigma: $0.5 \mu \mathrm{g} / \mu \mathrm{l})$. Images were recorded with the Metasystems Image Pro System (black and white CCD camera; Sandhausen, Germany), mounted on top of a Leica DM-RE fluorescence microscope [15].

\section{FISH Evaluation}

The FISH signals were interpreted by two analysts (MU, AH), who were blinded to the outcome data. Dysplastic areas were identified based on p16 staining and were scanned for FITC and TRITC signal copy numbers. The copy number was estimated as previously described to detect disomy, tetrasomy up to nonasomy by means of the determination of the maximum copy number and heterogeneity in formalin fixed and paraffin embedded tissue sections. The validity of this strategy was independently proven by means of a statistical analysis of spot counting in tissue sections [17, 18]. Lesions were classified are tetrasomic (copy number 4 ) in case a major fraction exhibited 4 copies, as aneusomic (copy number 3,4 ) in case a major fraction exhibited 3 copies and in case of minor fractions (copy number 2-4). Gain for the targets was noted when dysplastic areas were recognized with more than two copies for $3 \mathrm{c}$ or 3q. Subsequently, normal morphologic areas were analysed and consistently showed a disomy for $3 \mathrm{c}$ and $3 \mathrm{q}$.

\section{Outcome Measures and Criteria for Biomarker Performance}

The outcome measure was defined as the correlation between $3 q 26$ gain and disease persistence of high-grade CIN. No previous biomarker performance values are available for HLA types. The required test performance values include a high sensitivity and negative predictive value: lesions that will not regress spontaneously must be identified, as treatment is necessary in these women. The actual values depend on the follow-up term of observational management. Lower values can be accepted when strict histological follow-up is implemented to identify persisting lesions at an early stage.

\section{Outcome Measure and Statistical Analysis}

Quantitative variables were described as mean and ranges. Qualitative variables were described as frequency and percentage. Sensitivity, specificity, positive and negative predictive values were calculated from a $2 \times 2$ table. Sample size calculation was not feasible, due to the lack of comparable biomarker performance values and limitation of the study population by the availability of material.

\section{Literature Overview}

Eight studies were identified that evaluated the predictive properties of $3 q 26 / h T E R C$ gain in cervical squamous lesions [19-26]. All studies assessed patients with cervical squamous intraepithelial lesions who were followed for a certain period of time, without immediate treatment, in order to evaluate the natural prognosis of the lesions. The main study features are displayed in Table 1. Only two studies included patients with high-grade lesions. Heselmeyer-Haddad included patients with German PAP 3D cytology, which resembles CIN 1 or 2, of which the latter is interpreted as a high-grade lesion [19]. Ravaioli et al. included five patients with high-grade CIN [26].

\section{Study Results}

The main study results are summarized in Table 2. A total of 407 patients were included, of which 385 patients were diagnosed with ASCUS/LSIL/low-grade CIN and 22 patients were diagnosed with HSIL or high-grade CIN. Only five patients had a histological diagnosis of high-grade CIN. Pooling of the study results was not possible, due to a marked heterogeneity in patient populations, follow-up terms and outcomemeasures. Only five out of 155 patients (3.2\%) without $3 q 26$ gain showed disease persistence or progression.

\section{Summary and Appraisal}

All studies identify $3 q 26 / h T E R C$ gain as a potential prognostic marker in cervical precancerous lesions. 3q26/hTERC gain seems more frequent in persistent or progressive lesions, but positive predictive values are generally low: patients with $3 q 26 / h T E R C$ gain often show disease regression during follow-up. Negative predictive values are consistently higher: absence of 3q26/ $h T E R C$ gain seems to be a strong predictor of disease regression.

Nevertheless, several limitations of the individual studies and their review must be noted. Patient populations were generally small. Most studies included only patients with lowgrade lesions, which limits the evidence on the prognostic properties of $3 q 26 / h T E R C$ gain in high-grade lesions. The baseline diagnosis was not determined uniformly: some studies included patients based on cytology, whereas others included only histologically confirmed lesions. Furthermore, follow-up periods and methods differed: both cytology and histology was applied. Regarding the FISH analysis, the different studies did not apply a similar signal interpretation method and threshold for gain. Another important limitation 


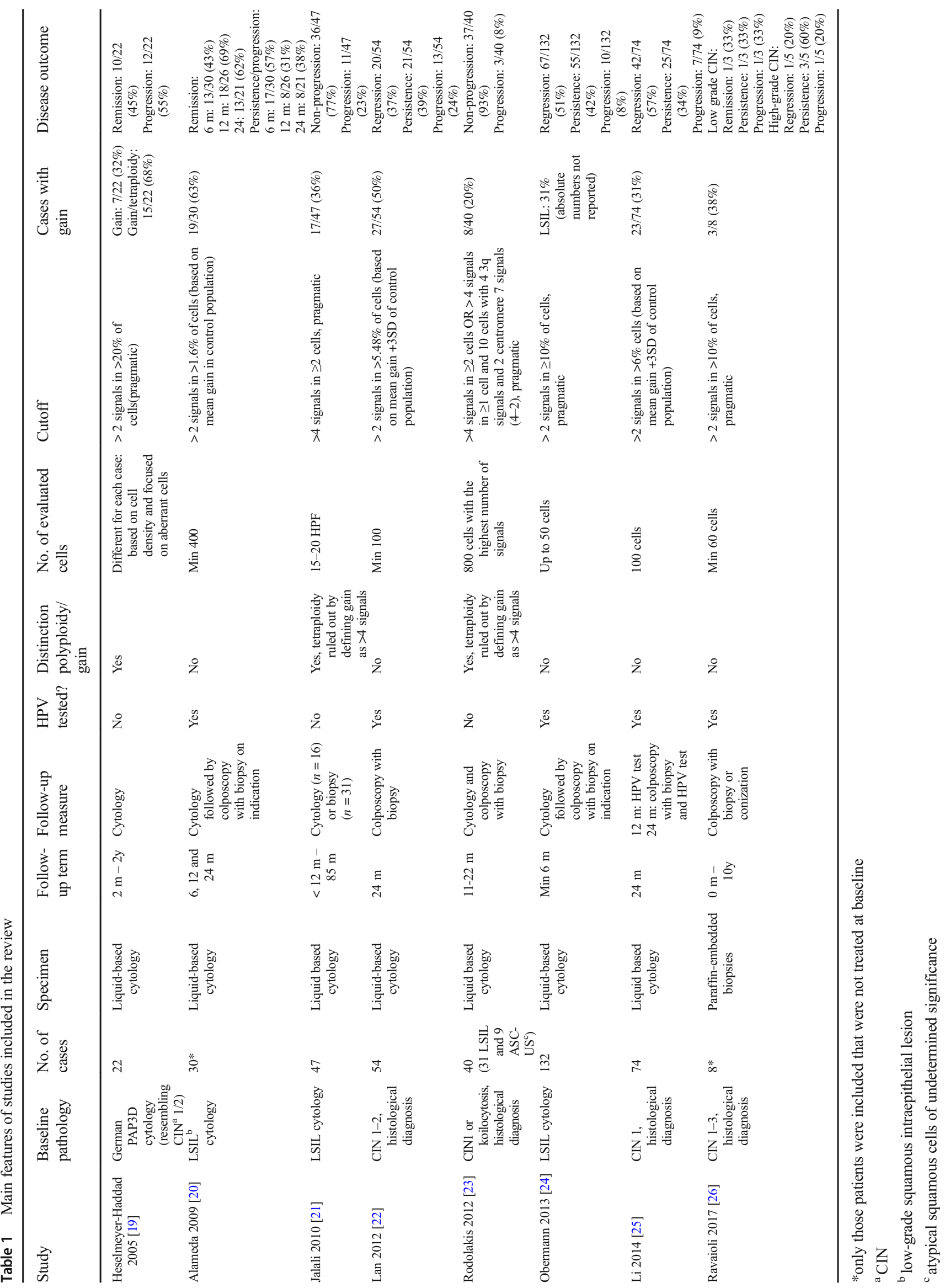


Table 2 Results of studies on $3 q 26 / h T E R C$ gain as a prognostic biomarker in CIN

\begin{tabular}{|c|c|c|c|c|}
\hline \multirow[t]{2}{*}{ Author } & \multirow{2}{*}{$\begin{array}{l}\text { Gain of } 3 q 26 / h T E R C \\
\text { per outcome group } \\
\text { (using study threshold) }\end{array}$} & \multirow{2}{*}{$\begin{array}{l}\text { Progression in } \\
\text { gain-negative group }\end{array}$} & \multicolumn{2}{|l|}{ Test properties } \\
\hline & & & $\begin{array}{l}\text { Prediction of persistence/ } \\
\text { progression vs regression }\end{array}$ & $\begin{array}{l}\text { Prediction of progression } \\
\text { vs regression/ persistence }\end{array}$ \\
\hline $\begin{array}{l}\text { Heselmeyer-Haddad } \\
2005 \text { [19] }\end{array}$ & $\begin{array}{l}\text { Only } 3 q 26 \text { gain: } \\
\text { Progression: } 7 / 12 \\
\text { Regression: } 0 / 10 \\
3 q 26 \text { gain and/or tetraploidy: } \\
\text { Progression: } 12 / 12 \\
\text { Regression: } 3 / 10\end{array}$ & $5 / 15$ & $\begin{array}{l}\operatorname{Sens}^{\mathrm{a}} 100 \% \\
\operatorname{Spec}^{\mathrm{b}} 70 \% \\
\mathrm{PPV}^{\mathrm{c}} 80 \% \\
\mathrm{NPV}^{\mathrm{d}} 100 \% \\
\text { (progression vs regression, only } \\
\quad \text { gain }+ \text { tetraploidy group) }\end{array}$ & \\
\hline Alameda 2009 [20] & $\begin{array}{l}6 \text { months: } \\
\text { Regression: } 7 / 15 \\
\text { Persistence/progression: 12/15 }\end{array}$ & NR & $\begin{array}{l}6 \text { months: } \\
\text { Sens } 80 \% \\
\text { Spec } 53 \% \\
\text { PPV } 63 \% \\
\text { NPV } 73 \%\end{array}$ & \\
\hline & $\begin{array}{l}\text { 12/24 months } \\
\text { Regression: } 8 / 18 \\
\text { Persistence/progression: } 6 / 8\end{array}$ & & $\begin{array}{l}\text { 12/24 months: } \\
\text { Sens } 75 \% \\
\text { Spec } 53 \% \\
\text { PPV } 43 \% \\
\text { NPV } 91 \%\end{array}$ & \\
\hline Jalali 2010 [21] & $\begin{array}{l}\text { Regression/persistence: 7/36 } \\
\text { Progression: 10/11 }\end{array}$ & $1 / 30$ & & $\begin{array}{l}\text { Sens } 91 \% \\
\text { Spec } 81 \% \\
\text { PPV } 59 \% \\
\text { NPV } 97 \%\end{array}$ \\
\hline Lan 2012 [22] & $\begin{array}{l}\text { Regression: } 2 / 20 \\
\text { Persistence: } 12 / 21 \\
\text { Progression: } 13 / 13\end{array}$ & $0 / 27$ & $\begin{array}{l}\text { Sens } 74 \% \\
\text { Spec } 90 \% \\
\text { PVV } 93 \% \\
\text { NPV } 67 \%\end{array}$ & $\begin{array}{l}\text { Sens } 100 \% \\
\text { Spec } 66 \% \\
\text { PPV } 48 \% \\
\text { NPV } 100 \%\end{array}$ \\
\hline Rodolakis 2012 [23] & $\begin{array}{l}\text { Regression/persistence: } 5 / 37 \\
\text { Progression: } 3 / 3\end{array}$ & $0 / 32$ & & $\begin{array}{l}\text { Sens } 100 \% \\
\text { Spec } 89 \% \\
\text { PPV } 50 \% \\
\text { NPV } 100 \%\end{array}$ \\
\hline Obermann 2013 [24] & $\begin{array}{l}\text { Regression: } 16 / 67 \\
\text { Persistence: } 15 / 55 \\
\text { Progression: } 7 / 10\end{array}$ & $3 / 54$ & $\begin{array}{l}\text { Sens } 70 \% \\
\text { Spec } 76 \% \\
\text { PPV } 30 \% \\
\text { NPV } 94 \% \\
\text { (progression vs regression) }\end{array}$ & $\begin{array}{l}\text { Sens } 35 \% \\
\text { Spec } 76 \% \\
\text { PPV } 58 \% \\
\text { NPV } 54 \%\end{array}$ \\
\hline Li 2014 [25] & $\begin{array}{l}\text { Regression: } 4 / 42 \\
\text { Persistence/progression: 19/32 }\end{array}$ & NR & $\begin{array}{l}\text { Sens } 59 \% \\
\text { Spec } 90 \% \\
\text { PPV } 82 \% \\
\text { NPV } 75 \%\end{array}$ & \\
\hline Ravaioli 2017 [26] & $\begin{array}{l}\text { Regression: } 0 / 2 \\
\text { Persistence: } 2 / 4 \\
\text { Progression: } 1 / 2\end{array}$ & $1 / 5$ & $\mathrm{NA}^{\mathrm{e}}$ & \\
\hline
\end{tabular}

\footnotetext{
${ }^{\text {a }}$ sensitivity

${ }^{\mathrm{b}}$ specificity

${ }^{\mathrm{c}}$ positive predictive value

${ }^{\mathrm{d}}$ negative predictive value

${ }^{\mathrm{e}}$ not applicable
}

in the interpretation of the study results is that HPV testing was not performed or reported in most studies. It is therefore unclear whether all lesions were HPV-induced. This limits the applicability of the study results to high-grade lesions, which are usually HPV positive. Moreover, HPV genotype is an individual predictor in the natural history of CIN lesions. As such, information on HPV status would improve the interpretation of the study data.

Despite all limitations, 3q26/hTERC analysis has been consistently identified as a prognostic marker in cervical precancerous 
lesions, with a high negative predictive value in mostly low-grade lesions. As such, evidence indicates a potential predictive role of $3 q 26 / h T E R C$ gain in the natural prognosis of cervical dysplasia, but clinical applicability is yet limited and the evidence on the predictive properties of $3 q 26 / h T E R C$ gain in histologically confirmed high-grade lesions is scarce $(n=5)$. This prompted us to perform a pilot study evaluating the predictive properties of $3 q 26 /$ $h T E R C$ gain in histologically confirmed high-grade lesions.

\section{Pilot Study: Results}

\section{Patient Characteristics}

A total of 19 women were included in our study. The mean age was 31 years (range 25-41). The mean interval between the initial colposcopy and the follow-up colposcopy with LEEP was 115 days (91-154 days). Nine women (47\%) showed disease regression during this follow-up period and ten did not $(53 \%)$. The mean age and biopsy-LEEP interval did not differ significantly between women who showed spontaneous regression and those who did not (mean age 32 vs 31 years, mean biopsy-LEEP interval 115 vs 114 days respectively).

\section{Lesions Characteristics: CIN Grade, Lesions Size, HPV Genotyping and p16 Staining}

Sixteen patients were diagnosed with a CIN3 lesion and three with a CIN2 lesion. Of the patients with a CIN2 lesion, two showed regression and one showed disease persistence (22 vs $10 \%, p=0.5$ ). In the original study, lesions were classified according to size in two categories: larger than $2.5 \mathrm{~mm}$ or equal to or smaller than $2.5 \mathrm{~mm}$. There was no difference between these two categories in terms of the number of women with and without regression: a lesion larger than $2.5 \mathrm{~mm}$ was found in 5/9 (56\%) women with disease regression and in $7 / 10(70 \%)$ women with disease persistence $(p=0.54)$. All women carried high-risk HPV. HPV-16 was found in 5/9 $(56 \%)$ women with disease regression and 7/10 (70\%) women with disease persistence $(\mathrm{p}=0.54)$. The biopsy material of all cases was p16 positive, confirming HPV infection.

\section{FISH Results}

Results of the $3 q 26$ analysis are shown in Table 3. Figure 1 shows typical examples of the FISH analysis. Four patients showed no $3 q 26$ gain, all of their lesions regressed spontaneously. Of interest, all CIN2 lesions showed $3 q 26$ gain. The test performance of $3 q 26$ gain in the prediction of natural prognosis of high-grade CIN in the study population is shown in Table 4 . When the analysis was restricted to only CIN3 lesions, the positive predictive value increased to $75 \%$, while the negative predictive value remained $100 \%$.

\section{Discussion}

This is the first study to assess the prognostic value of $3 q 26$ gain as a single genetic marker in the natural prognosis of exclusively high-grade CIN. The results show that $3 q 26$ gain is found in both women with persistence and regression of high-grade $\mathrm{CIN}$, but that none of the women without $3 q 26$ gain show disease persistence. This results in a high negative predictive value of $3 q 26$ for disease persistence. As such, the absence of $3 q 26 / h T E R C$ gain may potentially be applied to identify those lesions with a high potential of disease regression.

The test performance of $h T E R C$ gain in high-grade lesions in our pilot study is comparable to the test performance of $h T E R C$ gain in low-grade lesions, as reviewed in the literature. Negative predictive values were consistently high, while positive predictive values were much lower. The mediocre positive predictive value of $3 q 26 / h T E R C$ gain as a prognostic marker for disease persistence and/or progression may indicate that $h T E R C$ gain is a contributing, but not critical step in cervical oncogenesis. The development of cervical precancerous lesions and subsequent carcinoma is based on a complex interaction between virus and host, in which viral oncogenic properties and the human immune system influence the cellular processes that lead to cell transformation [8, 9]. In this process, several important molecular events have been identified, among which are viral DNA integration and upregulation of telomerase [8]. However, none of these events have been identified as critical steps or 'point of no return'. Indeed, upregulation of telomerase is not found in all high-grade CIN lesions or cervical carcinomas [12]. As such, it is unlikely that the prediction of the natural prognosis of CIN lesions will be based on one molecular event, but rather on a combination of viral, host and genetic parameters. Therefore, combining hTERC testing with other predictive biomarkers may lead to a test panel with a better overall test performance.

Interestingly, $3 \mathrm{q}$ gain can occur based on tetrasomy, in which four copy numbers are found, or aneusomy, in which three or more than four copy numbers are found. It is unclear whether there is a clinical difference between these two forms of $3 q$ gain, in terms of the risk of disease persistence or progression. Both tetrapoidy and aneuploidy are frequent events in CIN development. The frequency of tetraploid cells is significantly increased in CIN lesions compared to normal cervical tissue and is considered an early event in cervical carcinogenesis [27]. Aneuploidy is more often found in more advanced lesions and cervical carcinoma [15]. Although it is still debated whether aneuploidy results from genomic instability of diploid cells or from chromosomal losses from tetraploid cells, evidence in CIN lesions suggests that aneuploidy is preceded by tetraploidy [27]. This would indicate that aneuploidy in CIN lesions associates with later stages of cervical oncogenesis, possibly indicated a more high-risk CIN lesion. Based on these findings, one may argue that $3 q 26 / h T E R C$ 
Table 3 Results of $3 q 26$ analysis and natural prognosis in 19 patients with high-grade CIN

\begin{tabular}{lllll}
\hline Case & $3 q 26$ copy numbers & $3 c$ copy numbers & 3q status & $\begin{array}{l}\text { Regression } \\
\text { (yes/no) }\end{array}$ \\
\hline 96 & 4 & 4 & Gain & No \\
125 & 3,4 & 3,4 & Gain & No \\
159 & 4 & 4 & Gain & No \\
164 & 4 & 4 & Gain & No \\
170 & $2-4$ & $2-4$ & Gain & No \\
171 & $2-6$ & $2-6$ & Gain & No \\
182 & 3,4 & 3,4 & Gain & No \\
218 & $6-8$ & 3,4 & Gain & No \\
221 & $2-4$ & $2-4$ & Gain & No \\
225 & $2-4$ & $2-4$ & Gain & No \\
187 & $2-4$ & $2-4$ & Gain & Yes \\
192 & 4 & 4 & Gain & Yes \\
207 & 3 & 3 & Gain & Yes \\
222 & $2-4$ & $2-4$ & Gain & Yes \\
237 & 3,4 & 3,4 & Gain & Yes \\
194 & 2 & 2 & No gain & Yes \\
197 & 2 & 2 & No gain & Yes \\
200 & 2 & 2 & No gain & Yes \\
206 & 2 & 2 & No gain & Yes \\
\hline & & & & \\
\hline
\end{tabular}

gain based on aneuploidy imposes a greater risk of disease persistence or progression than 3q26/hTERC gain based on tetraploidy. In our study, the only purely aneusomic lesion showed disease regression. Our study shows no difference in disease regression or persistence based on $3 q 26$ gain in tetrasomic or aneusomic lesions, but numbers are small and the follow-up term was relatively short. The reviewed studies show conflicting results regarding the prognostic value of $3 q$ gain based on either aneuploidy or tetraploidy. One study showed a positive predictive value of $100 \%$ for gain based on aneuploidy for disease progression [19]. Two other studies
Table 4 Test performance of $3 q 26$ gain in the prediction of natural prognosis of high-grade CIN in 19 patients

\begin{tabular}{llll}
\hline & Persistence & Regression & Total \\
\hline Gain of 3q & 10 & 5 & 15 \\
No gain of 3q & 0 & 4 & 4 \\
Total & 10 & 9 & 19 \\
$p=0.0325$ & & & \\
Sensitivity: & & $400 \%(95 \%$ CI 66-100\%) \\
$\begin{array}{l}\text { Specificity: } \\
\text { Positive predictive value: }\end{array}$ & $67 \%(95 \%$ CI 39-87\%) \\
$\begin{array}{l}\text { Negative predictive } \\
\quad \text { value: }\end{array}$ & $100 \%(95 \%$ CI 40-100\%) \\
\hline
\end{tabular}

could not confirm this finding, but compared progression to non-progression (including persistence), which makes comparison of the studies difficult [21, 23]. Interestingly, Lan et al. found a higher progression risk for tetraploid lesions [22]. In conclusion, current evidence shows that lesions with $3 q 26$ gain based on both tetrasomy and aneusomy can show either regression, persistence or progression. Based on these results, it remains unclear whether there is a clinical difference between 3q26/hTERC gain based on tetrasomy or aneusomy, in terms of the risk of disease persistence or progression.

Only five out of eight reviewed studies performed HPV typing, of which only one study reported on the association between HPV and 3q gain: a non-significant association was found between viral load and 3q gain [20]. As discussed before, this limits the overall interpretation of the study results, since high-risk HPV in itself is a risk factor for disease progression/persistence. Regarding the relation between HPV infection and $3 q 26 / h T E R C$ gaing, it is debated whether $3 q 26 /$ $h T E R C$ gain a direct cause of HPV infection, or an independent risk factor in high-grade CIN. It has been shown that genomic integration of HPV (with increased expression of E6 and E7) and gain of $h T E R C$ are important associated
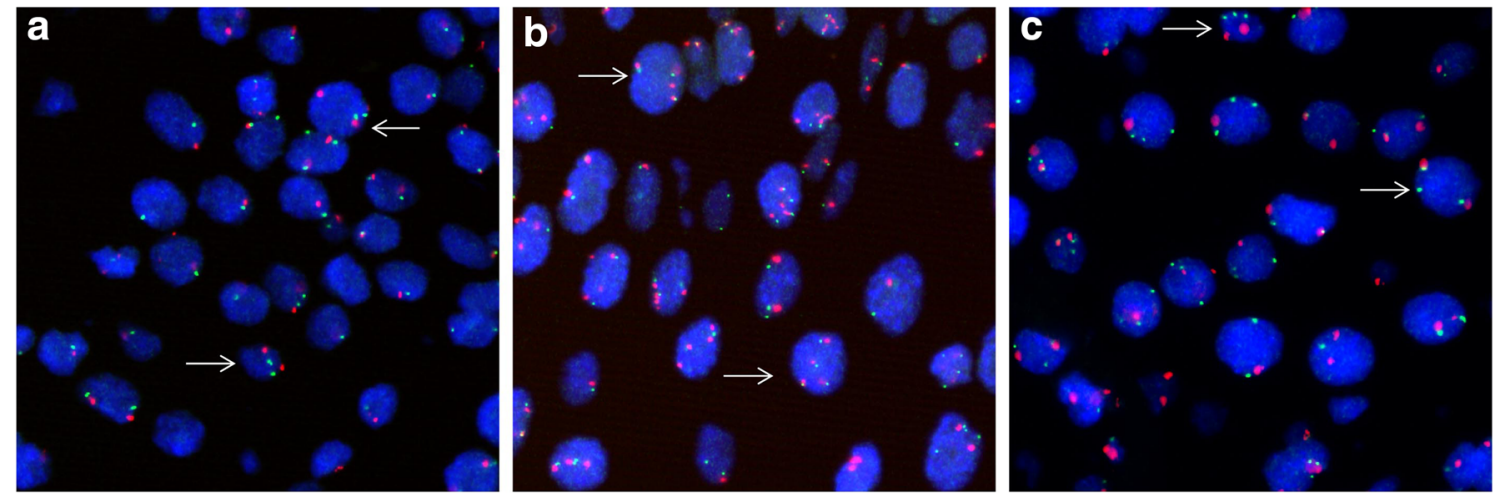

Fig. 1 Fluorescence in situ hybridization in high-grade CIN. Typical examples showing a disomy in (a) for both $3 q 26$ (green FITC signal) and 3C (red TRITC signal) (case number 197). In (b) a tetrasomy (case 192) and in (c) an imbalance between $3 q 26$ and $3 c$ (case 218). In the latter case the cells showed a ratio of 3 to 2 signals for $3 q 26$ and $3 c$ respectively, with nuclei with multiple copies for both targets (classified as gain). The arrows point to the nuclei with the typical signal distribution for the cases with no gain (a) and gain (b c) 
genetic events in the progression of CIN to cervical cancer [16]. On the other hand, $3 q$ gains have also been detected in non-HPV-associated squamous cell cancers of the lower genital tract and other malignancies [12]. Assessment of HPV status is therefore vital in future studies on the prognostic properties of $3 q 26 / h T E R C$. Furthermore, future studies should clarify the association between HPV genotype and 3q gain, with regard to the natural prognosis of high-grade CIN.

Limitations of the current clinical study include the small patient population. The patient population was extracted from a historical cohort of patients from a previous study, based upon the availability of sufficient biopsy material. Another limitation of our study may be the use of histological specimen instead of cytology for the FISH analysis, which has been shown to be more sensitive to the identification of cells with $3 q$ gain $[12$, 19]. We however chose to perform FISH analysis in biopsy material, as histology is the golden standard for a CIN diagnosis. A limitation regarding the interpretation of the study results, is the effect of a diagnostic biopsy on the natural history of the lesion. It is suggested that the biopsy itself may induce lesions regression. This would limit the interpretation of any prognostic marker, and applies to all studies on the natural history of CIN lesions. On the other hand, high-grade lesions are clinically diagnosed with a biopsy, making the prognostic effect of a prognostic biomarker clinically applicable despite the effect of the biopsy on regression itself. Another general limitation with regard to the interpretation and application of histological biomarkers in high-grade CIN is the possibility of false negative results due to sampling error, in which the biopsy is not representative of the actual disease status. We therefore propose that histological biomarkers should be applied as part of a biomarker profile, which should also contain biomarker that are independent of the disease histology. Examples are cytological, serological or epidemiological markers, such as HPV-genotype, immune markers and smoking status.

In conclusion, the results of the current review and pilot study show that the absence of $3 q 26$ gain could potentially serve as a prognostic biomarker for the identification of CIN lesions with a high probability of disease regression, preferentially as part of a broader biomarker profile. As such, $3 q 26$ staining could aid in the selection of women with low-grade lesions who would not need immediate colposcopic assessment and women with high-grade lesions who would not need immediate treatment. Both strategies could result in reduced costs, patient burden and side effects of surgical treatment. To confirm this hypothesis further research is necessary. Research should focus on identification of a generalized methodology for $3 q 26$ gain testing and interpretation. Subsequently, its prognostic properties should be confirmed in a larger patient population. Moreover, assessment of the association between HPV and $3 q 26$ gain is needed. Upon confirmation of its prognostic properties, $3 q 26$ staining could be considered as part of a biomarker profile to triage women with high-grade lesions for conservative follow-up measures.

Author Contributions MK, AK, TH and RK conceived and designed the study, IO and EJ provided patient materials, TH and MU performed the experiments, MK, AK and TH performed the data analyses and interpretation, MK drew the manuscript. All authors read and approved of the manuscript.

\section{Compliance with Ethical Standards}

Conflict of Interest The authors declare that they have no conflicts of interest.

Ethical Approval The study was performed in a historic patient cohort, for which ethics approval was previously obtained. IRB details: REK Vest (2012/1292-16, Document-id: 681901).

Ethical standards All procedures performed in studies involving human participants were in accordance with the ethical standards of the institutional and/or national research committee and with the 1964 Helsinki declaration and its later amendments or comparable ethical standards.

Abbreviations CIN, Cervical Intraepithelial Neoplasia; PPV, Positive predictive value; NPV, Negative predictive value; HPV, Human papillomavirus; $h T E R C$, Human telomerase RNA gene; LEEP, Loop electrosurgical excision procedure; FISH, Fluorescence in situ hybridization; ASCUS, Atypical squamous cells of undetermined significance; LSIL, Low grade squamous intraepithelial lesion; HSIL, High grade squamous intraepithelial lesion

Open Access This article is distributed under the terms of the Creative Commons Attribution 4.0 International License (http:// creativecommons.org/licenses/by/4.0/), which permits unrestricted use, distribution, and reproduction in any medium, provided you give appropriate credit to the original author(s) and the source, provide a link to the Creative Commons license, and indicate if changes were made.

\section{References}

1. zur Hausen H (2000) Papillomaviruses causing cancer: evasion from host-cell control in early events in carcinogenesis. J Natl Cancer Inst 92(9):690-698

2. McCredie MR, Sharples KJ, Paul C, Baranyai J, Medley G, Jones RW et al (2008) Natural history of cervical neoplasia and risk of invasive cancer in women with cervical intraepithelial neoplasia 3 : a retrospective cohort study. Lancet Oncol 9(5):425-434

3. Trimble CL, Piantadosi S, Gravitt P, Ronnett B, Pizer E, Elko A et al (2005) Spontaneous regression of high-grade cervical dysplasia: effects of human papillomavirus type and HLA phenotype. Clin Cancer Res 11(13):4717-4723

4. Ovestad IT, Gudlaugsson E, Skaland I, Malpica A, Munk AC, Janssen EA et al (2011) The impact of epithelial biomarkers, local immune response and human papillomavirus genotype in the regression of cervical intraepithelial neoplasia grades 2-3. J Clin Pathol 64(4):303-307

5. Munk AC, Gudlaugsson E, Ovestad IT, Lovslett K, Fiane B, Hidle $B$ et al (2012) Interaction of epithelial biomarkers, local immune response and condom use in cervical intraepithelial neoplasia 2-3 regression. Gynecol Oncol 127(3):489-494 
6. Grimm C, Polterauer S, Natter C, Rahhal J, Hefler L, Tempfer CB et al (2012) Treatment of cervical intraepithelial neoplasia with topical imiquimod: a randomized controlled trial. Obstet Gynecol 120(1):152-159

7. Barken SS, Rebolj M, Andersen ES, Lynge E (2012) Frequency of cervical intraepithelial neoplasia treatment in a well-screened population. Int J Cancer 130(10):2438-2444

8. Moody CA, Laimins LA (2010) Human papillomavirus oncoproteins: pathways to transformation. Nat Rev Cancer 10(8):550-560

9. Stanley MA (2012) Epithelial cell responses to infection with human papillomavirus. Clin Microbiol Rev 25(2):215-222

10. Litjens RJ, Hopman AH, van de Vijver KK, Ramaekers FC, Kruitwagen RF, Kruse AJ (2013) Molecular biomarkers in cervical cancer diagnosis: a critical appraisal. Expert Opin Med Diagn 7(4):365-377

11. Koeneman MM, Kruitwagen RF, Nijman HW, Slangen BF, Van Gorp T, Kruse AJ (2015) Natural history of high-grade cervical intraepithelial neoplasia: a review of prognostic biomarkers. Expert Rev Mol Diagn 15(4):527-546

12. Thomas LK, Bermejo JL, Vinokurova S, Jensen K, Bierkens M, Steenbergen R et al (2014) Chromosomal gains and losses in human papillomavirus-associated neoplasia of the lower genital tract a systematic review and meta-analysis. Eur J Cancer 50(1):85-98

13. Seppo A, Jalali GR, Babkowski R, Symiakaki H, Rodolakis A, Tafas T et al (2009) Gain of 3q26: a genetic marker in low-grade squamous intraepithelial lesions (LSIL) of the uterine cervix. Gynecol Oncol 114(1):80-83

14. Earley A, Lamont JL, Dahabreh IJ, Cowan J, Feldman S, Uhlig K (2014) Fluorescence in situ hybridization testing for the diagnosis of high-grade cervical abnormalities: a systematic review. J Low Genit Tract Dis 18(3):218-227

15. Hopman AH, Theelen W, Hommelberg PP, Kamps MA, Herrington CS, Morrison LE et al (2006) Genomic integration of oncogenic HPV and gain of the human telomerase gene TERC at $3 \mathrm{q} 26$ are strongly associated events in the progression of uterine cervical dysplasia to invasive cancer. J Pathol 210(4):412-419

16. Wright TC, Compagno J, Romano P, Grazioli V, Verma Y, Kershnar E et al (2015) Amplification of the $3 q$ chromosomal region as a specific marker in cervical cancer. Am J Obstet Gynecol 213:51.e1-8

17. Hopman AH, van Hooren E, van de Kaa CA, Vooijs PG, Ramaekers FC (1991) Detection of numerical chromosome aberrations using in situ hybridization in paraffin sections of routinely processed bladder cancers. Mod Pathol 4(4):503-513

18. Pahlplatz MM, de Wilde PC, Poddighe P, van Dekken H, Vooijs GP, Hanselaar AG (1995) A model for evaluation of in situ hybridization spot-count distributions in tissue sections. Cytometry 20(3):193-202

19. Heselmeyer-Haddad K, Sommerfeld K, White NM, Chaudhri N, Morrison LE, Palanisamy N et al (2005) Genomic amplification of the human telomerase gene (TERC) in pap smears predicts the development of cervical cancer. Am J Pathol 166(4):1229-1238

20. Alameda F, Espinet B, Corzo C, Munoz R, Bellosillo B, Lloveras B et al (2009) 3q26 (hTERC) gain studied by fluorescence in situ hybridization as a persistence-progression indicator in low-grade squamous intraepithelial lesion cases. Hum Pathol 40(10):1474-1478

21. Jalali GR, Herzog TJ, Dziura B, Walat R, Kilpatrick MW (2010) Amplification of the chromosome $3 \mathrm{q} 26$ region shows high negative predictive value for nonmalignant transformation of LSIL cytologic finding. Am J Obstet Gynecol 202:581.e1-5

22. Lan YL, Yu L, Jia CW, Wu YM, Wang SY (2012) Gain of human telomerase RNA gene is associated with progression of cervical intraepithelial neoplasia grade I or II. Chin Med J 125(9):1599-1602

23. Rodolakis A, Biliatis I, Symiakaki H, Kershnar E, Kilpatrick MW, Haidopoulos D et al (2012) Role of chromosome 3q26 gain in predicting progression of cervical dysplasia. Int J Gynecol Cancer 22(5):742-747

24. Obermann EC, Savic Prince S, Barascud A, Grilli B, Herzog M, Kaup D et al (2013) Prediction of outcome in patients with lowgrade squamous intraepithelial lesions by fluorescence in situ hybridization analysis of human papillomavirus, TERC, and MYC. Cancer Cytopathol 121(8):423-431

25. Li L, Jiang W, Zeng SY, Li L (2014) Prospective study of hTERC gene detection by fluorescence in situ hybridization (FISH) in cervical intraepithelial neoplasia 1 natural prognosis. Eur J Gynaecol Oncol 35(3):289-291

26. Ravaioli S, Tumedei MM, Amadori A, Puccetti M, Chiadini E, Bravaccini S (2017) Role of telomerase in cervical lesions as prognostic marker: a comparison between immunohistochemistry and fluorescence in situ hybridization. J Low Genit Tract Dis 21(1):42-46

27. Olaharski AJ, Sotelo R, Solorza-Luna G, Gonsebatt ME, Guzman P, Mohar A et al (2006) Tetraploidy and chromosomal instability are early events during cervical carcinogenesis. Carcinogenesis 27(2):337-343 